\title{
Implementation of Learning Courses And Cultural Customs of Aceh In The Historical Education of Study Program of Samudra University
}

\author{
Guntur Arie Wibowo ${ }^{1}$, Bachtiar Akob ${ }^{1}$ and Aulia Rahman ${ }^{1}$ \\ \{guntur.fkip@unsam.ac.id\} \\ Historical Education of Study Program, Universitas Samudra, Langsa, Indonesia
}

\begin{abstract}
In this study focused on knowing the implementation of traditional and cultural lectures in Aceh, to illustrate the results achieved in the implementation of this learning, and to know the obstacles faced in the implementation of learning. The research method is qualitative descriptive method. The strategy in this study used a single case study, by first determining the focus of the study. Source of data taken from informants, activities and documents. Data collection using observation techniques, in-depth interviews and document recording. Next, to check and verify the data, use the triangulation technique. Implementation of learning looks not optimal because there are some things that are not relevant between lesson plans with implementation. The results of the implementation of learning, seen from the results of learning to get good results, but that need to be considered aspects of the assessment is still not complete because it is only seen from the aspects of cognitive and psychomotor. Obstacles encountered in the implementation of learning is the method and teaching materials and learning strategies used. Then this learning activity turned out to produce some positive aspects for students such as aspects of education, inspirational aspects, and aspects of recreation.
\end{abstract}

Keywords: Learning, Customs and Cultural of Aceh.

\section{INTRODUCTION}

Aceh is a region where there are a wide variety of ethnic groups that has the diversity of customs, ordinances, languages, arts, crafts, skills etc. Therefore the diversity should always be preserved and developed with retaining the excelency values through education. The introduction of environment, social and Acehnese culture to students that allows them to get involve in their surroundings, better understand the cultural heritage from the ancestor.

Through education in this respect is the college, this education is better known as history of customs and culture. The history of customs and culture in college in Aceh should be viewed as one of the possible alternative that can be selected and applied by bringing students in what is called a Living History, history from the environment around them. The question is, why? This is because in learning the history of the customs and culture of Aceh will likely lead to development of insights in teaching history. This is supported by the opinion of Klein 
that "Learning can be defined as experiencing process that results in relative states, maturation, or innate response tendencies [1]. This definition of learning has three important components. First, learning reflects a change in the potential for a behavior. Learning does not automatically lead to a change in behavior. We must be sufficiently motivated to translate learning into behavior". By this, the student is expected to be more passionate in following lectures and gain the benefit greater than the process of analytical study.

Through teaching of the Acehnese customs and culture history the Acehnese students are invited to get closer on the real situation of the closest environment. Next, bringing students directly to know and live the community environment, where they are part of it. Exactly when it says that the teaching of Acehnese customs and culture history was able to break through the boundaries between "World College" with the "real world" outside of the college. This is in the opinion of Hilgard and Bower cited by Snelbecker [2], "learning is the processby which an activity originates or is changed through reacting to an encountered situation, provided that the characteristic of the change in activity cannot be explained on the basis of native response tendencies, maturation, or temporary states of the organism". By teaching Acehnese customs and culture history student will get plenty of examples and experiences from the different levels of society development, including the current situation. They will also be more inclined to develop special skills as a matter of observation, asking or doing interviews, selecting sources, looking for facts, etc.

Yet again, the success of a learning not regardless of how motivation and high discipline of lecturers and the support of their students. Some of action which can be done includes, Firstly, the professor simply tooks examples from the customs phenomenon and culture of Acehnese to give explanations of historical material that is being taught. Secondly, by guiding students out of classes to do research by observing directly the historical sources and collect historical data (go to museums, historic sites, or even interview). Lastly, case studies are needed to be prepared for longer and gradual (students involved in choosing the topic, making the activities plan, carrying out such a plan from heuristics to historiography stage).

From the three forms of teaching Acehnese customs and culture history in the college, the second way is relatively approached the target i.e. less spending the time, but invites/involves the students to do research outside the classroom though in simple way. As the choice, process take precedence over results, certainly in motivating students to develop particular skills are needed when doing fieldwork, so the students can skip the dullness in learning history.

In conclusion, in the system of learning the role of professors and students is equally dominant, especially for learning in College, in addition to other components such as the material and the environment is not as important in the learning process. Therefore. the researchers examine how implementation of learning courses and cultural customs of aceh in the history study program of Samudra university.

\section{METHODS}

The research approach used in this research was the qualitative approach with a descriptive form. According to Bogdan and Taylor in the Moleong [3] qualitative methods are procedures that produce descriptive data in the form of words written or spoken of people and behavior that can be observed. In addition, because of the problems and the focus of the research is already determined before plunging into the field, then the strategy research specifically may be referred to as case studies were established (embedded case study 
research). According to Soetopo [4] says that "the source of the data in qualitative research can be a resource (the informant), event or activity, place or location, objects, images and recordings." While according to Lofland cited in Moleong [3] states that: "the primary source of data in qualitative research is the words and actions of the rest is additional data such as documents and others".

The technique of sampling is a special form or process for centralizing or election in the research that points on a selection (Goetz and Le Comte in Soetopo [5]). In this study researchers using the technique of sampling with aims (purposive sampling technique) to determine the informant. the selection of informants based on analysis i.e. informant deemed to know and can be trusted to be a steady source of data and figure out the problem in depth [5] , i.e. the coordinator of history education study program in Samudra University, lecturer and students as participants of the courses, to keep the confidentiality of our informants identify each result of the interview with the letter "S" followed by the serial number (S1, S2 ...), the location of research is history education study program and documents, which include: the syllabus and SAP as well as used textbook.

\section{RESULT AND DISCUSSION}

\subsection{Lecturers Understanding Toward School-Based Curriculum (KTSP)}

History education study program in Samudra University, KTSP is still the applied curriculum in it. In short, things that need to be understood in relation to KTSP for lecturer is that KTSP was developed in accordance with condition KTSP units of education, potential and characteristics of the region, as well as social culture of local people and learners. Things that is needed to be prepared in KTSP are, (1) Syllabus which includes: SK and KD. The learning material and the indicators of achievement, (2) Learning implementation plans/RPP which includes: learning objectives, Instructional Material, method/ Strategies of learning, Media, learning resources and evaluation or assessment. From the results of observation and interviews, it can be obtained from portrayal that lecturers of history education study program can already understand KTSP.

In KTSP, syllabus is basic elaboration of competencies and competency standards into learning materials, learning activities and indicators of achievement of the competencies for assessment of learning results. Development of these components is the absolute authority of lecturers, including development of syllabus format and the addition of other components. The more detailed syllabus can help lecturers in outlining the lesson plan.

The successful of learning depends heavily on the success of the learning materials that lecturer have designed. Learning material in fact is part of the syllabus, namely planning, projections and predictions about what will be done at the time of learning activities. An overview og lecturers understanding toward KTSP looks at the material being taught, the achievement of basic competencies and competency standards by considering the potential of learners and the allocation of time, the example of the standard of competence "learners can strengthen the mastery and broadening the competence of scientific knowledge and expertise in the field of the history of the customs and culture of aceh "with basic competence" Explain the meaning, urgency, and the object of the study of the history of Acehnese customs and culture " outlined in the syllabus and learning material that is explained in the meaning of history of Acehnese customs and culture, urgency of history of Acehnese customs and culture aceh and the object of the study of the history of Acehnese customs and culture. 
Learning activity starts with opening, the core activities and closing, and then assign the method i.e. lecture and question and answer. This type of assessment written test with essay form. This standard task that most major professors associated with the lesson plan (RPP) KTSP syllabus outlines are based into the RPP that are more detailed and operational, as well as ready to be taken as guidelines or scenarios in learning [6]. Then, from the results of the data analysis through observation, it can be obtained from portrayal that history of customs and culture lecturer has been ready to apply KTSP, it has been proved in the preparations that is done by lecturer maximaly.

\subsection{Learning Implementation}

The core of the Organization of education is the implementation of learning that is done by lecturer in the classroom. The implementation is learning activities between lecturer and students. In this activity the lecturer should be able to use all its capacity to carry out the learning stage by stage as in the lesson plan that has been prepared or compiled before. In addition, in realizing the lesson plan, lecturer must be able to manage the class both in the ability of the opening lecture, the lecturer's attitude in the learning process, the ability of presenting learning materials/material, ability in implementing learning strategies, the use of media and learning resources, detail in time setting, motivate learners, enabling learners so that learning takes place in a living, active, creative and fun. Learning that really excite learners so as to obtain a meaningful learning experience and obtain results in accordance with learning objectives, this means learning implementation phase includes the preparation of tools and learning activities that consists of the initial activities, the activities of the core and the cover.

In the preparation phase, the lecturer has made the syllabus and lesson plan (RPP) independently, but not out of the example that has been given by the government. In the RPP, the lecturer do three activities, namely early activities, core activities and cover activities.

In the initial activities in class, the lecturer opens with precencing and giving the general explanation related material being taught.

"Children, yesterday I have said about the examples of cases of traditional history and culture of Aceh with the approach of social history such as the case studies on the process of customary marriage in the community of Aceh Tamiang and Peusejuk Adat, the differences and similarities. Furthermore, for today's meeting, I will continue the lecture material about the life cycle material of the people of Aceh". (S1)

The core activities in the form of exposure to the explanation is made during 20 minutes. When the lecturer explain with lectures method, learners are seen noticed, many learners who noted, during the learning process does not appear some students who fell asleep, there are only a few that look speak to their friends and play their handphone. After the question and answer session is finished, the lecturer does not do follow-up activities. The lecturer continued at closing activities by giving greetings to learners.

Preparation of the RPP by history of Acehnese customs and culture lecturer is still very simple, the RPP was designed for one basic competence, basic competence in which one covers the entirety of each meeting. Aspects such as the achievement side of cognitive, affective and psychomotor not shown.

Based on the results of observation can be inferred that the lecturers have yet to implement learning programs that have been created. These conditions resulted in the mismatch between the RPP with learning implementation, otherwise it will not produce a good quality of learning according to Winkel [7] that the quality of learning depends on how 
teachers provide information, how the teacher presents the material, how teachers provide reinforcement, teaching how to awaken and enable the learners involved in the learning process. All that range in didactic skill owned by teachers.

"If this course is not there, write it on the blackboard for the media is not there yet". (S2)

The researcher analizes that the use of media should be optimized so that everything that is delivered can stimulate the mind, get attention and interest of learners to learn. So, if all those things are implemented, certainly the purpose of education generaly and specifically can be achieved.

"The media is not used, just telling stories and lectures, so writing on the board, have never used the media". (S3)

The researcher analysis on the use of media found that there are three main functions, which one of the function is the purpose of instruction that should involve learners in the form of real activities so that learning can occur optimally and is not monotony. In mastering material, a history lecturer have already mastered the teaching material, this is due to the history of Acehnese customs and culture lecturer has educational background in history.

Analysis the researcher found that lecturers' understanding of material is very important as their duty to transfer the knowledge, where lecturers are required to be able to become a reference for learners in providing material.

Learning process in history of Acehnese customs and culture education courses is applied through learning in the classroom. Classroom learning is done through several methods, including using lectures and faqs, case studies and assignments. Some of these methods are also applied in the course of history of Acehnese customs and culture including lecturing methods and question and answer. lecturing methods and faqs found that are less attractive so that learners get bored easily because tose are monotony.

The researchers analizes that lecturers are supposed to use various methods to make learning procss more interesting and fun. In the end, the use of various learning methods will provide more value namely, for the lecturer, the variation of learning methods will be able to facilitate the delivery of the subject matter to students. In addition, it can also create a condition of learning that is not monotonous, so that learning is not boring and preferred by learners. This opinion is corresponding with Davies [8], in the selection of methods, a lecturer should be based on the criteria, namely the nature of the learning objectives are achieved, the need to enrich the learning experience and the ability of the learners are covered in the task. It means that the suggestions in teaching changed the behaviour of learners into appropriate behavior. For the learners, the various methods in learning process can increase their learning interest.

The researcher reflection analysis result, lesson plan of history of Acehnese customs and culture that is compiled by lecturer in accordance with KTSP reference, both in terms of systematics as well as components that are outlined, but its essence is less appropriate. Implementation of the learning that was carried out was not appropriate with the lesson plan made that use projectors as a media. The readiness of a lecturer in performing learning in general is ready and a device of learning such as syllabus and RPP also already exists. Implementation of learning still not following KTSP, this is shown from the use of method in teaching is dominated by the method of lecture and without using the learning media.

\subsection{The Result of Learning Inside Classroom}

Assessment of learning results from students that is conducted by the lecturers is not only to monitor the process, progress and development of the learning results of students in 
accordance with their potential, but also feedback to lecturers in order to refine the planning and learning process.

On the aspect of assessment, lecturers do written assessment, tasks assessment and attitude assessment, the form of a written test consisting of a midterm (UTS) and a final exams (UAS) plus three times of the tasks value. Whereas, the task form of midterm or final exams are essay or elaboration. From this assessment the result is processed into the value in end of the semester.

Based on the observation of UTS values and UAS values, it shows that the learners in the form of a materials mastery which include knowledge and understanding, are good on average. Learners' learning aspect, attitude and skills, in general it can be said better. It can be shown that learners have a positive attitude in the following course, like pay attention when lecturer explains, actively record to what was explained by the lecturer and do well the task given.

The successful implementation of history of Acehnese customs and culture, it is reinforced by the existence of the supporting factors of success. Some of the supporting factors can be further elaborated, for example, it can be seen from the ability of a lecturer in mastering the material and lesson plan. Any material that was taugh previously has been consulted by experts team who drafting the material. The selection of the material to be taught must be adapted to the area of expertise in teaching. Thus, the ability of material mastery and the lesson plan can be the lecturer ability. The factor of learning methods selection, observation methods and classroom are considered suitable as a learning method in to be delivered in the history of Acehnese customs and culture course, since the substance of the subject matter can be applied at the time of the field observation is in progress. From the learners curiosity factor, it can be seen that before they implement their active observation, asking questions and seeking information of historical objects which may be allowed as a matter of observation or research.

\subsection{The Result of Learning Outside Classroom}

As expressed earlier that in the history of education, the learning process has always emphasized on the achievement of learning objectives that is formulated into several competencies which one of them are pedagogic competencies, personality, professional and social. In the process of learning, the fourth such competence was made as referral for the achievement of learning objectives are being carried out. If such criteria of lecturers professionalism are met, those things will change the role of the lecturer from passive into creative and dynamic. Lecturer professional development becomes the global concern, because lecturers' duty and role is not only to provide science and technology information, but also to create the attitudes and the spirit that is able to survive in hipercompetency era.

Assessment in terms of the result quantity values at the time the evaluation was carried out by giving written exam either UTS or UAS to learners after learning activities in the classroom are completed. In this way, the lecturers will be able to see how far the level of knowledge and understanding of learners towards the material presented. While the assessment process conducted by the lecturer by observing the pattern of behavior of the learner while carrying out field observations. In addition, the process assessment is also useful to know how far the students have the attitude of empathy towards the learning environment.

"To improve the learning achievement, so to improve the achievement we provide the training of students to write, so that later learners will be accustomed to writing, and will become a habit, which in turn they are able to make a scientific paper research, and the 
impact can make mapping that can be included in the creativity program of learners. Once he got used to writing observations, he could propose in October to follow PKM (Student Creativity Program). For the results of the exam semester, the value is relative, just by learning to write history there is an interest to better understand the local cultures. That's our main goal like that. For the achievement in class yes as it is-that, every end of the learning process that is the end of the semester we assign learners to do field observations related to local history, eg philosophical values in traditional Song-Song dance in Aceh Tamiang or many others, each region has its own uniqueness, well that we assign them to them carefully and kaji, and we also do not let go. We also will accompany them by always evaluating the way they research. So that we also do not need to go directly to the field, they are enough we terjunkan with the provision of knowledge and understanding of the correct research techniques. They will then know that their environment is part of a large piece of history and has such broad insights. From there we can see the process of workmanship when it is appropriate we give the value in accordance with the final results achieved. That's from the field assignment, while to obtain academic results, we always hold the midterm exam and final exam of the semester. Well from there we will know how far the understanding of learners about the material delivered by the lecturer ". (S4)

After conducted the analysis, the researcher believes that the evaluation of learning that is conducted aims to know the achievement of basic competencies that have been determined. With this basic competence can be known the level of mastery of both the standard of the material by students in terms of aspects of intellectual or creativity or to assess the effectiveness of the program implemented.

According to the recognition of the learners, the assessment system is done after the class activities take place, ie learners are required to make an observation report about the customs contained in their respective areas. This is done to see understanding of the customs and cultures that exist in their respective regions. The assessment system can be seen from the results of observation and writing reports conducted. For that, learners are expected to prepare themselves related to the lecture material of traditional history and culture Aceh maximally, when will carry out research. Preparation of the learners are done by making the observation report maximally, that is by searching the source of information as much as possible and study carefully, before written in the report. For the assessment process, achievement indicator becomes the authority of the lecturer, namely the implementation of process evaluation can be done by lookinh at how the behaviour and the interaction of learners in the implementation of observation activities write report. To evaluate the results can be done by giving some lecture material that has been set before then held a test or exam to know the mastery of the material. Both evaluations should be continous, so they are an important set of evaluations in learning.

According to observations made by examining the document of the work of the student observation report, the result is as follows, this report was prepared by some students, including discussing "The philosophical values in traditional Song-Song dance in Aceh Tamiang". Based on the observations, the authors conclude that the observation tasks performed are still simple, the learners have not worked optimally. This is evident from the results of research that looks not deep and is only fundamental. This means that the lecturer in assigning the task, still can not be understood by the learner, so it is suggested for later on when the lecturer give the task of observation report, the learner must be given good knowledge and researching procedure, so that the report will be sequential and accompanied with data or complete evidence.

Analysis of researchers, that the assignment to learners in the form of making observation reports research a particular object, this is very good because this is a contextual learning. 
Learners not only understand the material but in the end will also understand the methodology in the study. But before they are released to carry out research activities, should be given enough stock so that at the time of the final report writing process, they are able to write the research well and complete.

Other results achieved from field observation activities can be seen and known from two points of view, namely from the lecturers and learners. From the lecturers, the achievement of this field observation activity is the lecturer can be easier to deliver the subject matter to the students, because it is done by looking directly at the historical objects in their respective area. Such activities are also useful in the context of transferring knowledge contextually, applying constructivist thinking, and providing an understanding of field research. Then, according to the recognition of the learners, the achievements of field observation activities such as learners can add knowledge insight to the historical objects in their own areas. In addition, it can train students to conduct critical analysis of the historical objects they examine in their observation activities.

Based on the results of field observations that researchers do, it can be analyzed that, the method of learning applied by lecturers very appropriately applied in the lectures of traditional history and culture aceh this, because it is done by direct fielding learners of the objects of study of customs and culture in the region they are each. With these activities will equip learners to understand their own philosophical values and can be a source of support in learning the history of adat and aceh culture in the classroom.

"The measure of success, is they managed to compose the origin of an area both customs and culture. So this is in addition to the final exam of the semester that became the benchmark of learning outcomes of learners, I will also assess them from the results of the task from the beginning of the semester I have given that is composing a regional origin in each area of learners. I will give them a stimulus with an understanding of concepts and appropriate steps in the research, and I will also always accompany them, when they are confused what to do, yes I help with consultation like sharing. They will arrange the task of research is the form of observation report, and that later I will value, both in terms of results and research procedures, for learners who process and the results well yes will be good value". (S5)

Reflection on the results of the analysis of the researchers, that the results achieved learning Indigenous History and culture aceh, can be seen from two aspects, namely the evaluation of the quantity of the results of written test scores and evaluation of the quality of the process when learning through field observation activities take place. The results achieved in the learning in terms of quantity of values can be seen from the test results after the course materials are completed, while the assessment in terms of process, can be seen by observing and assessing the work of learners at the time of writing the observation report. Both of these achievements can be used as a criterion of the success of learners in taking the subject of Traditional History and aceh culture.

"I from the beginning of this local history lecture told my students to make an observation report, which will be collected at the end of the semester. From the beginning I gave them knowledge about the methods and techniques of research, so they were able to research in the field. And this task I do not limit this must be so, I release them to explore the potential of historical objects in their respective regions. Besides they will have experience they will also get knowledge about the correct research process. Well from there indirectly I have implemented a contextual learning process is not just a matter of lectures in class ". (S5)

"If I think, perhaps with the activity of the assignment of the observation report we will be able to understand the material described in the class, so we can practice directly in the 
field not just imagine. In addition, with the assignment we will practice writing scientific papers, which later we can use in the future as in making a thesis or another Mr. " (S6)

"With us studying it, we will be able to understand more about course material because we not only hear during college but we can also directly practice what we get in class". (S7)

The results achieved in teaching Indigenous history and aceh culture through classroom learning and observation can also be seen and known from two perspectives, namely from the lecturers and learners. In addition, the achievement of learning through classroom activities in the classroom and at the time of observation took place also contains three important aspects, namely educational aspects, inspirational aspects and aspects rekreatif. These three aspects become important factors of successful learning through the classroom and field observation.

\subsection{Obstacles Faced}

Implementation of the learning of traditional and cultural subjects of Aceh is closely related to the lesson plan (RPP), the selection of topics and strategies and instructional media used by the lecturers, so it can be known obstacles or difficulties faced by lecturers. In the selection of topics or customs and culture material of Aceh lecturers have been referring to the existing SK or KD. For learning strategy depends on existing facilities and infrastructure. However, for the case of the traditional and cultural subjects of Aceh, the lecturer has not used the appropriate media with the competence to be achieved as the learning strategy, and this is felt less impressive and monotonous. The selection of media should be tailored to the material and competencies that the learners must achieve. This is in accordance with Mulyasa (2004: 56), facilities and learning resources selected and used in the learning process if appropriate and support the achievement of basic competencies.

Another obstacle analysis is the difficulty of elaborating the standard of competence into syllabus in planning the learners' learning experiences, identifying the competencies according to the needs and problems faced by the learners, as well as describing the subject matter of learning, because the learning experience to be provided is tailored to the ability / creativity of lecturers is also different.

Another inhibiting factor, derived from the lecturers themselves, ie in terms of learning strategies. Among them in the selection and application of methods, and approaches in learning. According to Mulyasa [6], teachers must master the principles of learning, selection and use of teaching methods, and selecting and using learning strategies and approaches. In terms of learning methods, the obstacles experienced are the difficulty of choosing the appropriate method with the competencies to be achieved during the learning activities take place. To overcome obstacles in the selection and use of methods, lecturers should try to see and recognize the characteristics of learners in order to choose the right method, that is by looking at the condition of students and existing facilities, trying to be a facilitator in the learning process, and improving the relationship between the study program with parents of learners. To overcome barriers about the learning approach used, lecturers should seek more information about methods and approaches in learning and try to apply them. In addition, lecturers also need to discuss with many other lecturers about the approach in learning and its application.

In addition, obstacles for lecturers in the implementation of learning that is about evaluation. The lecturer has conducted an assessment that includes the cognitive, affective, and psychomotor aspects. Of the three domains of this most difficulty is the assessment of the affective domain. This is because there is no clear scoring standard for the assessment of the affective domain, so that the lecturer has difficulty to provide an assessment. Consequently, 
affective domain assessment still tends to be subjective. Lecturers are also difficult to monitor learners continuously, this observation is needed to really know the attitude and circumstances of learners in following the learning process. To overcome these problems, lecturers should be in every teaching and learning activity, need to make notes about the students who are good and not good, or can also use the observation sheet.

\section{Conclusions}

It can be said that the lecturers of Aceh's traditional and cultural subjects have had a fairly good understanding of KTSP. This is demonstrated through his understanding of the concept of KTSP, Syllabus and RPP. In the preparation stage in the implementation of learning, lecturers have developed learning tools independently and well. Only, entering the stage of learning activities, lecturers do not conduct learning activities according to the RPP he compiled. Based on the results of UTS and UAS values that have been implemented by learners, shows that they are able to master the material presented by the lecturer.

With the method of giving the task of field observation, lecturers try to invite learners to study the objects of cultural studies in Aceh society, in order to obtain the information needed in the lecture and later as an archive or as their final project.

In learning through this method of observation turned out to produce some positive aspects, including educational aspects, namely aspects related to the improvement and understanding of the lecture materials, inspirational aspects, namely aspects related to motivation to continue to develop themselves, and aspects of the recreative aspects that are related with pleasure. All three aspects are intertwined into a single unit, so that achievements in field observation activities should also be able to accommodate these three aspects.

\section{References}

[1] S. B. Klein, Learning Principles and Applications. New York: Mc Graw Hill, 1996.

[2] G. E. Snelbecker, Learning theory, instructional theory, and psychoeducational design. New York: McGraw-Hill Companies, 1974.

[3] L. Moleong, Metodologi Penelitian Kualitatif. Bandung: Remaja Rosdakarya Offset, 2006.

[4] H. Soetopo, Metodologi Penelitian Kualitatif (Dasar teori dan terapannya dalam penelitian). Surakarta: Universitas Sebelas Maret Press, 2002.

[5] H. Soetopo, Penelitian kualitatif: Dasar teori dan terapannya dalam penelitian. Surakarta: Universitas Sebelas Maret, 2006.

[6] E. Mulyasa, Kurikulum tingkat satuan pendidikan (KTSP). Bandung: Remaja Rosda Karya, 2007.

[7] W. S. Winkel, Psikologi Pengajaran. Jakarta: Gramedia Widiasarana Indonesia, 2005.

[8] I. K. Davies, Pengelolaan Belajar. Jakarta: PT. Rajawali Pers, 1987. 